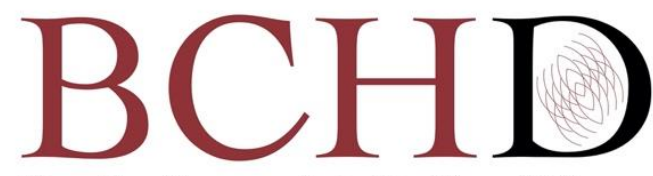

Bioactive Compounds in Health and Disease

\title{
Japan's health food industry: An analysis of the efficacy of the FOSHU system
}

\author{
Alina Adany ${ }^{1,2}$ Hunter Kanya ${ }^{2,4}$, and Danik Martirosyan ${ }^{1,2} *$ \\ ${ }^{1}$ University of Pennsylvania, Philadelphia, PA, USA; ${ }^{2}$ Functional Food Center Inc., Dallas, TX, USA; ${ }^{3}$ The University of \\ Colorado Denver, CO, USA; ${ }^{4}$ Functional Food Institute, San Diego, CA, USA
}

Corresponding author: Dr. Danik Martirosyan, Functional Food Institute, San Diego, CA, USA

Submission Date: March 20 th 2021; Acceptance Date: April 23 ${ }^{\text {rd }}$, 2021; Publication Date: April $30^{\text {th }}, 2021$

Please cite this article as: Adany, A. Kanya, H. Martirosyan, D. Japan's health food industry: An analysis of the efficacy of the FOSHU system. Bioactive Compounds in Health and Disease $\quad 2021 ; 4(4): 63-78$.

DOI: https://www.doi.org/10.31989/bchd.v4i4.795

\section{ABSTRACT}

Health claims and their regulations have been a contended topic globally with varying degrees of standardization. Japan is one of the most advanced countries in terms of their view on the regulation of health claims and their role in the food industry. With the introduction of functional foods in 1984, Japan put health claims to use by informing consumers of specific health benefits of food products marketed and sold to them, while also cutting down on inflated and false claims made by food manufacturers. This was done with the establishment of Foods for Specified Health Uses (FOSHU) a few years later. Although extremely strict and sometimes problematic,

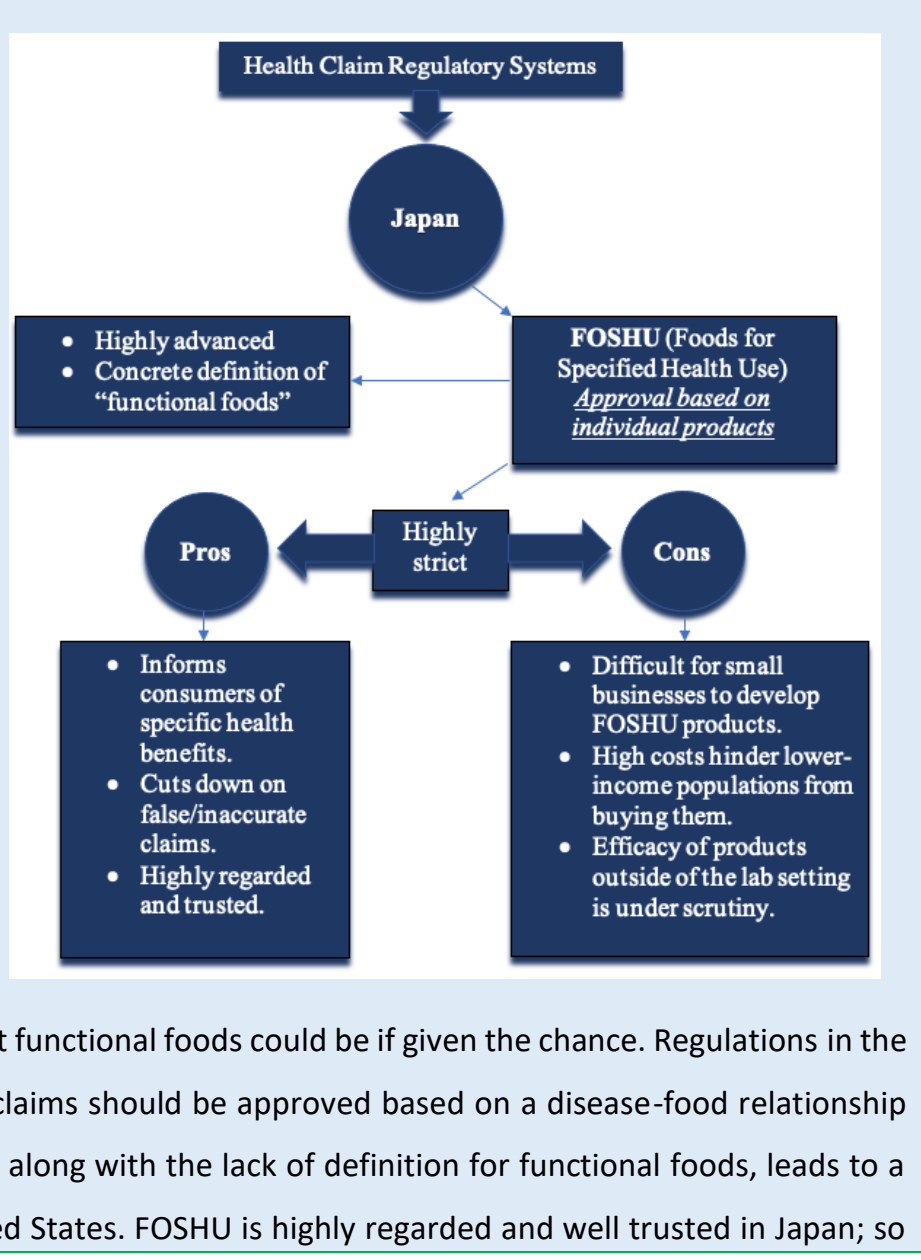


much so that FOSHU products and packaging helps promote non-FOSHU products with similar appearance. Yet, despite the system's tightly controlled mechanism, its efficacy and comprehensiveness to the average consumer has come under question. Due to tight regulations and the high costs and long wait times of developing FOSHU products, many small businesses find it difficult to apply for them. Subsequently, this trickles down to consumers and inhibits lower-income populations from purchasing these products. Additionally, the effectiveness of FOSHU products outside of a clinical setting has come into question from the scientific community. Factors including poor consumer education regarding FOSHU, as well as clinical settings that do not mimic the daily life of consumers have produced unsatisfactory results in the general public.

Keywords: FOSHU, Health Claims, Functional foods, After market research, Clinical setting, functional/active ingredient, FOSHU seal

CFFC 2020. This is an Open Access article distributed under the terms of the Creative Commons Attribution 4.0 License (http://creativecommons.org/licenses/by/4.0)

\section{INTRODUCTION}

Health claims are a controversial topic in the food industry and the regulations that come with them are even more so. This is an issue that crosses international borders and involves many specialists, including policy makers, public health specialists, as well as the industries that control the foods and drinks that are being consumed by the public. The regulations that attempt to control the issue are changing constantly in order to accommodate emerging science. These policies must amend the previous strict prevention of health claims that affirm the ability of the product to prevent, treat, or cure diseases as new information becomes available. Though places such as the United States and the European Union (EU) have placed regulations as well as made categorical boundaries in order to control the health claims put out by companies, the first place to make a functional system for these health claims was Japan.

In 1984, the term "functional food" began to be developed. The main goal at the time was to use food products with known health benefits to post health claims on their food labels in order to keep the rising elderly population as healthy as possible. This was critical at the time as, along with an increasing percentage of elderly citizens there was a low birthrate and low immigration rate, placing a heavy burden on the Japanese healthcare system. This was the beginning of the FOSHU system that is established in Japan today [1].

All food in Japan is regulated under the Food Sanitation Law, which oversees the safety of all products, imported or domestic. It is a notoriously strict system in which food additives must be on a positive list, otherwise they are not allowed in, even if those food additives are being widely used in North America and the EU. There have been multiple requests for additions to the positive list of additives, and although progress has been slow, the Ministry of Health Labor and Welfare (MHLW) has been responsive to change. This has been true to other sectors of food in Japan, including Genetically modified organisms (GMOs) and agricultural chemicals as Japan looks to other countries when modifying their own regulations. This has led to a rapid change in food regulation in Japan and is a fact 
that is important to remember when analyzing the Japanese functional food system [1].

FOSHU is the most tightly regulated functional food system in Japan. It is regulated by the MHLW and has special labeling to let consumers know that they are consuming a FOSHU product. Each of these products go through a thorough review of safety and efficacy and only then are approved for FOSHU status. Additionally, each product also includes at least one functional ingredient to which the claims are attributed to [1]. The system requires both in vitro and in vivo studies along randomized trials and is generally recognized as a system that produces products with little to no danger to consumers. In fact, many food regulatory systems including the EU are trying to incorporate some of the core FOSHU principles into their own regulations. In comparison, the United States approves its health claims on a claim-basis rather than on a per product basis, which means each product is not tested for its efficacy. FOSHU regulations have the potential to serve as a guide to the developing Food and Drug Administration (FDA) policies and give the United States the ability to carve out an official place for functional foods [2].

Regulations of health claims in the United States differ from FOSHU in a few ways. For one, health claims authorized under the FDA draw relationships between a food or food component and a disease. This means that the active ingredient may not have to be explicitly identified so long as the "food product has an authorized health claim instead of a component." FOSHU regulations, however, require the food product to have an identifiable active compound to which the health claim will be assigned on an individual product basis rather than trusting that each food product that has been assigned a health claim will have the same effectiveness. Additionally, the FDA allows a specific disease to be mentioned in comparison to FOSHU's health claims which refer to "maintenance or promotion of health." Meanwhile, other organizations in the United States have come up with systems for approval of health claims and eventually, functional foods. One of those organizations is the Functional Food Center which works with the goal to help "facilitate communication and collaboration" among nutritional scientists studying functional foods around the world. The Functional Food Center has also developed their own definition of functional foods which currently states that functional foods are:

\section{"Natural or processed foods that contain biologically-active compounds, which, in defined, effective, non-toxic amounts, provide a clinically proven and documented health benefit utilizing specific biomarkers, for improving general health, for the prevention, management and treatment of chronic and viral disease or its symptoms."}

The process for identifying and approving a functional food according to the Functional Food Center is very similar to that of FOSHU with a few key differences (Figure 1): Mainly, the Functional Food Center believes in conducting epidemiological studies after a product is released in order to assess its effectiveness. This, along with more specific ratios and thorough instructions needed for a product and the addition of identification of biomarkers differentiates the FOSHU process from the Functional Food Center's process [2]. This can be especially 
important during times of pandemics when the public requires varied methods of staying healthy.

Yet although the Japanese government is endorsing a safe system that is meant to produce foods with enhanced nutrition that will improve the health of its citizens, the question of its efficacy outside of clinical trials is yet to be firmly determined. This review will analyze the effects FOSHU on the perception of healthy food by the public, as well as the efficacy results consumers find when using FOSHU products. Furthermore, this article has a second goal of also clarifying the Functional Food Center's position on functional foods. This analysis looks to take the benefits from the FOSHU system and elucidate how the Functional Food Center can implement these benefits, while improving or avoiding the problems within the FOSHU system.

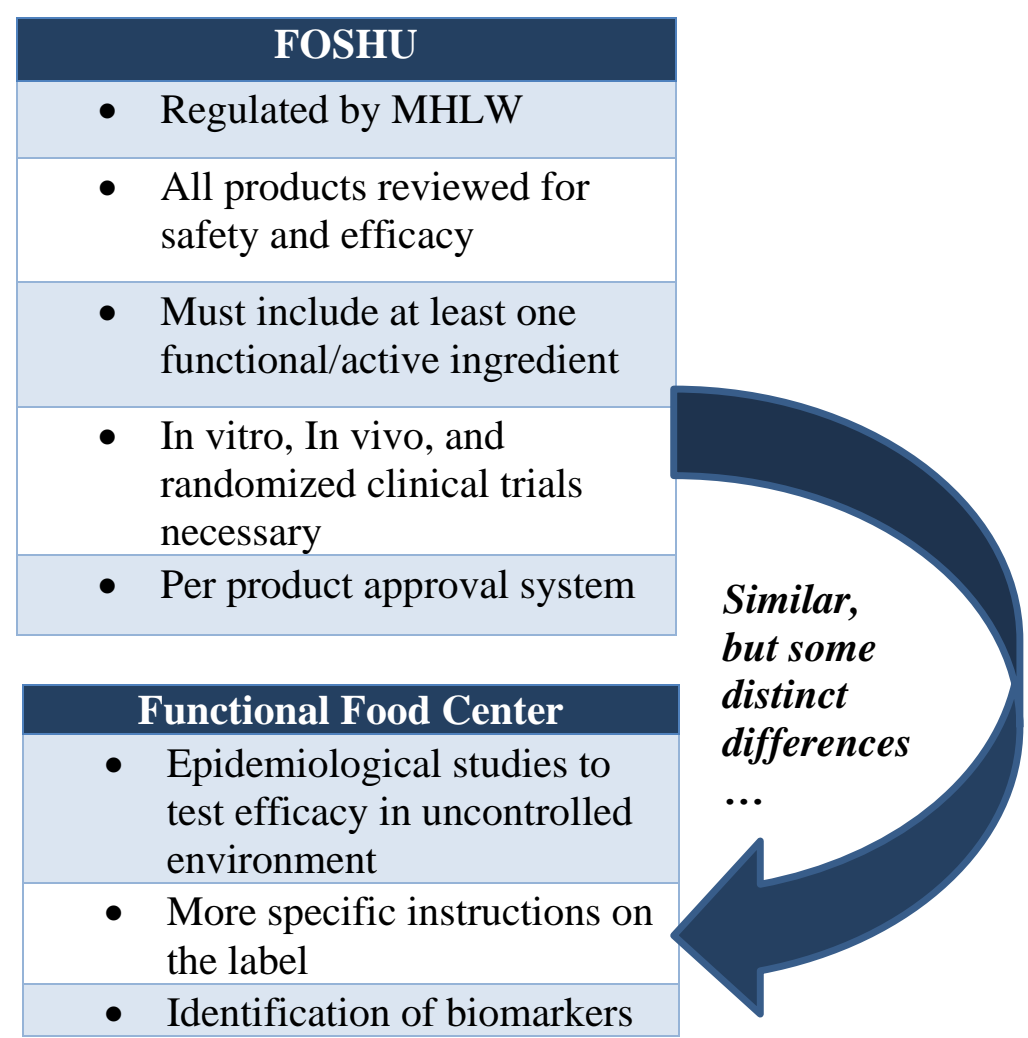

Figure 1: Similarities and differences between FOSHU and the Functional Food Center for the process of identifying and approving a functional food.

The Consumer Market and General Perception of FOSHU: As the market for health foods develops rapidly around the world, there are bound to be differing opinions of its efficacy and value. FOSHU is no exception to that. The addition of more products into the system raises awareness of its presence and allows for a wider audience to draw their own conclusions. This is especially important as the public's opinion is a big deciding factor in the survival of a market. The evolution of FOSHU throughout the years brought branches and derivatives of the Japanese health food market. Table 1 details all of the sectors mentioned in this review. 
Table 1. FOSHU and FOSHU Derivatives

\begin{tabular}{|c|c|c|}
\hline Category & Description & Established \\
\hline FOSHU & $\begin{array}{l}\text { Foods for Specified Health Use: } \\
\text { Foods officially approved to claim their physiological effects on the } \\
\text { human body }\end{array}$ & 1991 \\
\hline FNFC & $\begin{array}{l}\text { Foods with Nutrient Function Claims: } \\
\text { Foods that are labeled with the functions of nutritional ingredients } \\
\text { (vitamins and minerals) }\end{array}$ & 2001 \\
\hline $\begin{array}{l}\text { FFC (Food } \\
\text { with } \\
\text { Functions } \\
\text { Claim) }\end{array}$ & $\begin{array}{l}\text { Food with Functions Claims: } \\
\text { Allows food manufacturers to post function claims based on scientific } \\
\text { evidence submitted to the Consumers Affairs Agency (CAA), usually } \\
\text { through systematic reviews. }\end{array}$ & 2015 \\
\hline FHC & $\begin{array}{l}\text { Food with Health Claims: } \\
\text { foods that comply with the specifications and standards established by } \\
\text { the MHLW and are labeled with certain nutritional or health } \\
\text { functions. This group is further broken down to FOSHU and FNFC. }\end{array}$ & 2001 \\
\hline $\begin{array}{l}\text { So-called } \\
\text { health } \\
\text { products }\end{array}$ & $\begin{array}{l}\text { Conventional foods that are sold or used as items useful for } \\
\text { maintenance and improvement of health }\end{array}$ & 2001 \\
\hline
\end{tabular}

A public outlook: A big factor in understanding consumer choice of FOSHU is the marketing behind the products and the information available to the public. It is known that FOSHU allows companies to post health claims on their products in order to announce their nutritional value. It is a voluntary claim made by the manufacturer, which many American consumers would be hesitant to trust, yet if a FOSHU logo is printed on the packaging, many Japanese consumers will trust the health claims presented to them. In order to understand why this difference is present, there needs to be an understanding of the information given on the packaging of products. In the USA, along with the EU and other Asian countries, it is mandated by the government to have nutritional labeling on food products. This is not the case in Japan. Most often the only information available to consumers are the health claims made on the front of the packaging, if they are present at all. Therefore, it can be assumed that Japanese consumers rely on the health claims made by companies when buying nutritional foods. As FOSHU is a trusted government regulatory system, consumers are likely to trust products bearing its logo, giving companies an incentive to gain FOSHU approval as it would mean a higher sales revenue.

From this, it can be hypothesized that the FOSHU seal is the most impactful component of the packaging, and as health claims can be seen as a part of a product's marketing, consumers are less likely to trust them. More so, it can also be hypothesized that the FOSHU seal affects consumer's perception of other products in the same category, and that this effect is stronger when a FOSHU and non-FOSHU 
products share similar packaging. In order to test these hypotheses, researchers from Keio University in Japan conducted a survey study consisting of two segments and involving 280 undergraduate business students in the age range of 18-23. In the first survey, participants were asked to rate a jelly drink brand on a nine-point scale system based on their belief of how healthy the drink was in the presence or absence of the FOSHU seal. The results of the first segment of the study showed consistency with the first part of the hypothesis: students were more likely to rate the FOSHU brand drink as the healthier option regardless of the health claims made on the package (Table 2).

Table 2: Study 1; Hypothesis 1. FOSHU seal is more impactful on ratings of healthfulness than health claims. Units: Nine-point belief scale regarding healthfulness (9: "very good" - 1: "very bad") [3].

\begin{tabular}{|l|l|l|}
\hline $\begin{array}{l}\text { Nine-point belief scale regarding } \\
\text { healthfulness (9: "very good" }-1: \\
\text { "very bad") }\end{array}$ & FOSHU Seal Present & FOSHU Seal Absent \\
\hline $\begin{array}{l}\text { Health Claim Present } \\
\text { Health Claim Absent }\end{array}$ & 6.11 & 4.76 \\
\hline
\end{tabular}

In the second segment, participants were divided into four groups: group 1 was asked to rate a FOSHU product and a non-FOSHU product with similar packaging to the FOSHU product, group 2 were asked to rate a FOSHU product and a non-FOSHU product with different packaging from the FOSHU product, group 3 were asked to rate a non-FOSHU product with similar packaging to the FOSHU product, and group 4 was asked to rate a non-FOSHU product with

Table 3: Study 2; Hypothesis 2. FOSHU seal affects consumer's perception of other products in the same category; this effect is stronger when a FOSHU and non-FOSHU products share similar packaging. Units: Nine-point belief scale regarding healthfulness (9: "very good" - 1: "very bad") [3].

\begin{tabular}{|l|l|l|}
\hline $\begin{array}{l}\text { Nine-point belief scale regarding } \\
\text { healthfulness (9: "very good" } \\
\text { "very bad") }\end{array}$ & $\begin{array}{l}\text { Exposure to FOSHU } \\
\text { Brand }\end{array}$ & $\begin{array}{l}\text { No Exposure to FOSHU } \\
\text { Brand }\end{array}$ \\
\hline Similar Packaging & 4.86 & 3.09 \\
\hline Dissimilar Packaging & 3.25 & 4.02 \\
\hline
\end{tabular}

Based on the findings of this study, it can be concluded that the FOSHU seal carries great weight in different packing to the FOSHU product. The results of the second segment confirmed the second part of the hypothesis; participants were more likely to perceive the non-FOSHU product as healthier if a FOSHU product was available in the same category and were even likelier to rate the non-FOSHU product as healthy if the packaging matched that of the similar FOSHU product (Table 3). 
that a lot of research is conducted prior to the approval of a product, as well as the lack of additional information that would allow consumers to compare similar FOSHU and non-FOSHU products [3]. As more accessible ways of gaining government approval are available to smaller companies such as the Foods with Nutrient Function Claims (FNFC) system and the Food with Health Claims (FHC) system, it would be helpful to make nutritional panels mandatory in addition to the health claims and the FOSHU seal in order for consumers to make more informed choices.

Public perception translates to the success of the market: The effectiveness of product marketing ultimately comes down to the willingness of the consumers to not only buy the product, but also to pay the asking price. This relies heavily on consumer perception and attitude towards a product, and in the functional foods market this is a critical factor as it is still a relatively new sector. Like in many other countries, Japan's health food market depends on the health claims that can be advertised to consumers. Unlike many other places, however, Japan has the regulatory body of FOSHU to ensure the credibility of health claims, and as established previously, FOSHU is a recognized and valued voice in the health food industry. Therefore, although companies that have received the FOSHU label are not the only ones selling health foods, or functional foods, the FOSHU seal has been proven to be a great enticement for consumers. In order to discover how valued the FOSHU seal is in terms of money, Mitsunori Hirogaki, an assistant professor at Ehime University in the department of
Industrial Management designed a study in order to evaluate the impact of health claims posted on functional foods in Japanese university students.

The study was conducted in Hiroshima where "the incomes and preferences of its residents closely resemble those of an average Japanese consumer" and involved 265 participants aged 18-25. Along with the health claims, several other aspects were studied, including the country of origin, the size, and the price of the product. One product, a green tea drink, was analyzed in order to decrease confusion. The study concluded that consumers value both health claims made by FOSHU and the country of origin of the product. While FOSHU is trusted due to government affiliation, country of origin is significant as "consumers often considered farm products from domestic suppliers as being high in quality and safety" and this belief is confirmed through a survey by the Japan Finance Corporation (Figure 2).

The results of the study show that the marginal willingness to pay (MWTP) for the FOSHU branded green tea was approximately $¥ 45$, which was the second highest among the factors. Meanwhile, the factors of size and price of the product proved to be insignificant in consumer choice. However, while the size of the container was an insignificant factor, the volume of the contents seemed to be negatively correlated, meaning participants were more likely to choose the container with a smaller volume compared to a larger volume. This is likely due to the fact that healthy food is perceived as having poor taste, therefore influencing consumers to buy less. The study concludes that both the country of origin 


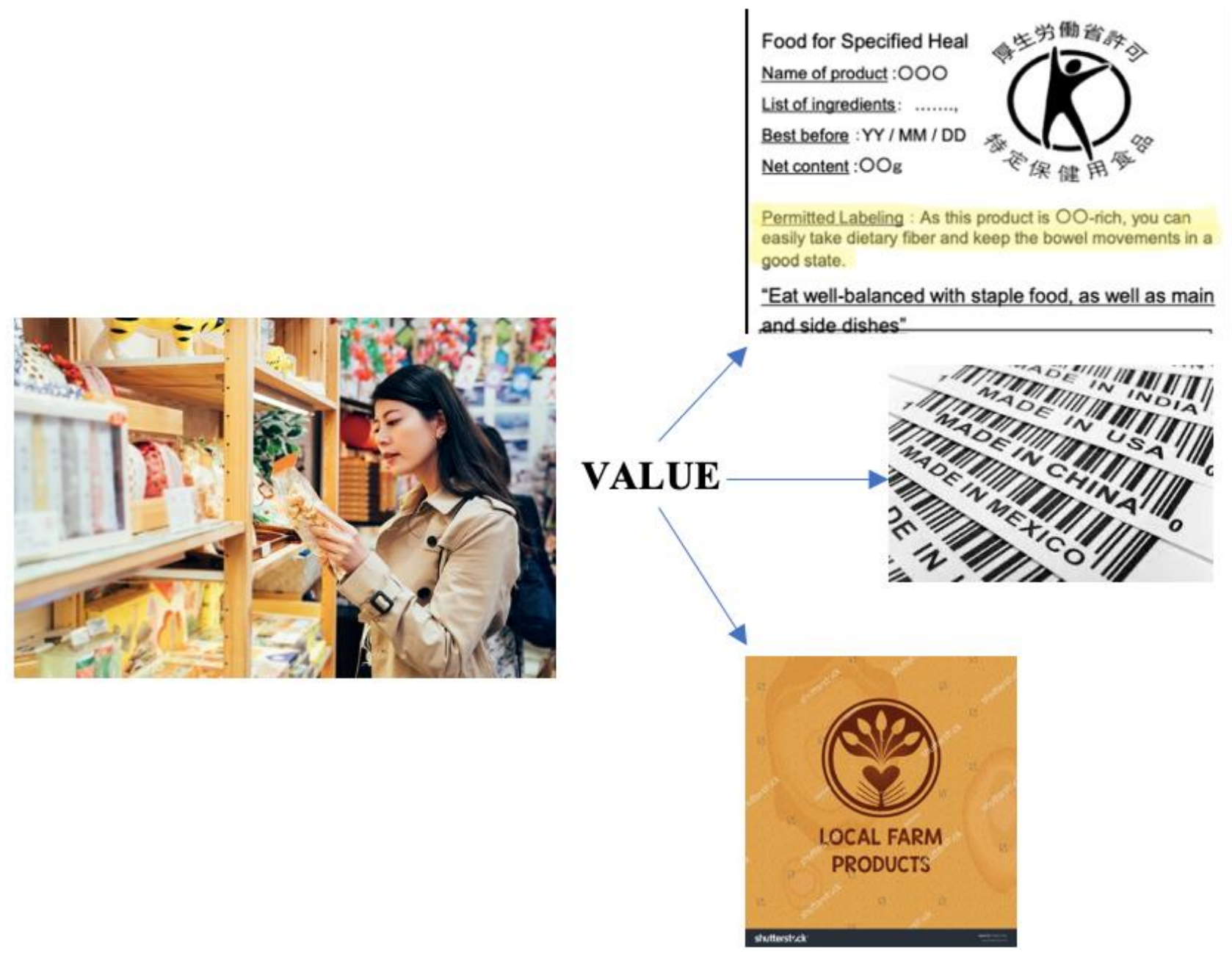

Figure 2: Japanese consumers most value FOSHU logo and claim, country of origin, and farm products from domestic suppliers.

and the FOSHU seal have a great impact on consumer behavior when analyzing the health food market in Japan [4].

Although the experiment showed possible implications for the effects of the FOSHU seal, another factor of the market is those who actually consume FOSHU products. A study done on the sociodemographics of 56,537 grocery shoppers between the ages of 15-69 over the span of four years found that both the amount and type of functional foods chosen was based on the financial and education status of the consumers. Nearly 8,238 participants out of the sample had never bought a functional food item over the four-year period of the data collection
[5]. Generally speaking, functional foods are bought as a small part of an individual's overall groceries. Out of those who did buy functional foods, FOSHU products made up more than $5 \%$ of groceries for only $25.86 \%$ of households, and although the difference was small, there was a higher consumption of functional drinks from elderly people compared to young ones. This might indicate that older consumers are more health conscious than younger consumers [5].

In regard to the influence of economic factors on the consumption of FOSHU, it was found that lowincome households tended to avoid functional foods. When functional foods were purchased in low- 
education households, they were mostly staple foods which include items such as bread, rice and cereal. Among high consumers of staple foods also included the elderly, women, and high-income level households. However, there was an overall trend of a higher functional food consumption in males [5].

Economic factors affect the general health of a population. Household income is related to greater health achievement, and as low-income households tend to buy less healthy food overall, less health satisfaction is seen in those populations. While the rigorous research that companies must do in order for their products to be FOSHU approved ensures a quality product, it also drives the pricing of the FOSHU up as companies must recover the costs [5]. This translates to exclusion of low-income households from the health food market. For this reason, the authors suggest government subsidies to FOSHU as a means for their products to become available to all household income levels.

A medical perspective: As FOSHU products are marketed to the public as nutritional support for maintaining good health, the awareness of those in the medical field is important in order to guide the public on their proper use. One sector of healthcare that is often overlooked is the pharmaceutical branch. Pharmacists often communicate to patients any possible issues or side-effects of their medications, however, there isn't much research done regarding the communications with patients about any health products they are consuming and the possible effects they might have on an individual, as well as the possible interactions with a patient's medications. (Figure 3).
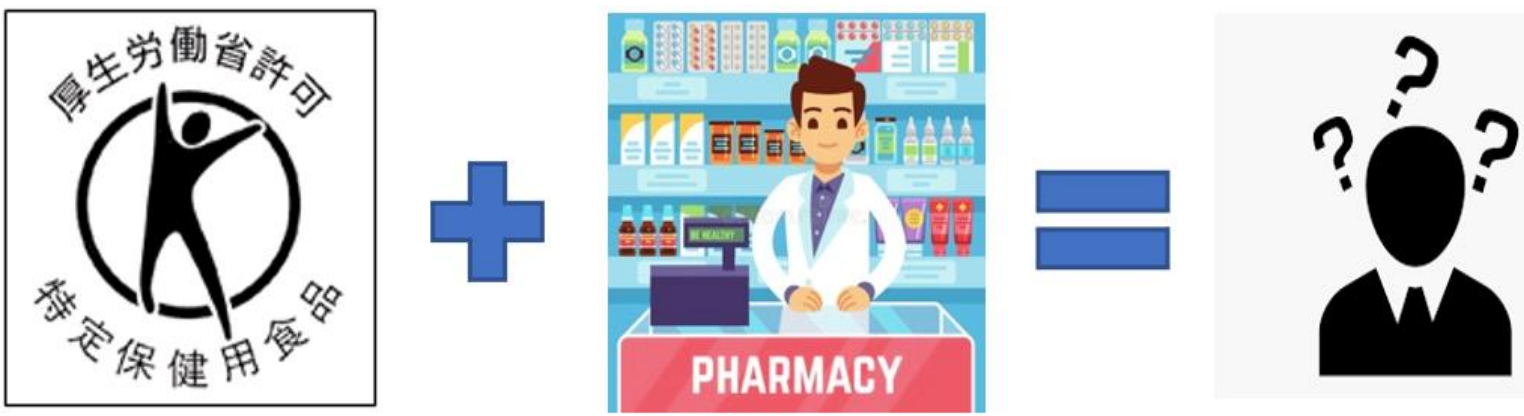

Figure 3: (Left FOSHU logo) [6]. Pharmacists lack education for the use of these health products and cannot effectively communicate about them with their patients.

The term "health products" is the combination of "foods with health claims" (FHC) and "so-called health products". FHC is then further divided into two legally defined subsections which are FOSHU and FNFC. A study from the International Journal of Clinical Pharmacy conducted a study of pharmacist's knowledge and comfort with functional foods and focused on the large category of "health products" in order to gain a broader perspective [7]. Questionnaires were sent out to a sample of pharmacists and the study received a total of 16 responses from different working backgrounds including a clinical setting and retail store pharmacy positions. There was an overall negative response to patient use of health products. While some pharmacists were uncomfortable with discussing the consumption of health products due to lack of scientific evidence, as well as lack of knowledge regarding proper and safe use, others had concerns 
regarding adverse effects as well as a decrease in patient compliance with their medical regiment [7].

Though opinions varied from each participant, there was a main complaint of insufficient training on health products which proved a significant barrier when communicating with patients. One pharmacist expressed her reluctance to sell any health products as she knew little about their effectiveness, and when asked about her response to patients' inquiries, she simply stated "I tell patients that they're good for health" [7]. While this sample in this study was small, it shows a greater issue with functional foods from an educational stance; not only is there a need for consumers to educate themselves about health products, but there is also a dire need for medical training in those products to help guide patients along in their choices.

Criticisms of the System: While FOSHU has been the poster child of functional food management since it was first developed in 1991 in Japan, it does not always hold up to its high standards. Like many regulatory systems, FOSHU has received a fair amount of criticism in regard to its operation. These seem to come from Japan alone as the foreign outlook on FOSHU upholds the regulations set by the system. This section will discuss areas for improvement in FOSHU.

\section{The application process of FOSHU and its derivatives:}

When it comes to functional foods regulations, Japan is the go-to model. There is strict oversight over the application process, from the significance of clinical results to documentation on the stability of the active ingredients in the products. Manufacturers must go through six different agencies to be able to label their products as "FOSHU approved", often taking months of reevaluation and correction of documents and thereby, a lot of funds as well [8]. Yet the system that was built to control the claims on health foods in Japan, is also working against many manufacturers. Food advisory consultant, Kiyoko Kubomura states that the FOSHU application process can take anywhere from 6 months to 3 years, costing companies around 1-2 million USD [8]. Although this might seem like a step taken to reduce false claims and dangerous products, few applications for FOSHU approval have been denied over the years. Instead, applications simply stand still while requests for more information stall the approval. Meanwhile, FOSHU is not a requirement for companies to market so-called "health foods". This means that companies that have not invested in a FOSHU approval seal can take active ingredients found in FOSHU products, construct a different formulation for their product, and achieve the same functionality. This works to indirectly penalize companies applying for FOSHU approval while discouraging future applicants $[8,9,10]$. It has been established before that the public has strong trust in FOSHU and that the seal of approval increases the price of the products, thereby increasing profit for the companies. Yet these increased prices may also exclude members of society with lower income from experiencing any benefit from the products. More so, small businesses have trouble keeping up with larger companies as they do not have as many funds to gain FOSHU seals for many of their products. Table 4 summarizes the problems manufacturers face with the FOSHU process. 
Table 4: Shortcomings of the FOSHU approval process for manufacturers.

\section{Application Process for FOSHU Products Works Against Manufacturers}

- Length: 6 months to 3 years

- Manufacturers must go through six different agencies to be able to label their products as "FOSHU approved."

- Reevaluation and correction of documents.

- Often more information is requested, and this stalls the process.

- Cost: \$1-2 million USD

○ Extensive paperwork process.

- More difficult for small businesses with less funds.

- Indirect Penalization for companies applying

○ Marketing "health foods" does not require FOSHU.

- Companies can use active ingredients of previously approved FOSHU products and market these to consumers.

- Discourages future applicants.

This has been a concern for the Japanese government as well, and they have been working to deregulate the FOSHU system and allow for more growth in the functional food sector. This began in 2001 with the "Food with Nutrient Function Claims" (FNFC) [9]. This subsection of FOSHU was created in order for foods to be sold as supplements to the consumer's nutrition that are insufficient in their normal diet. While using the FNFC label, companies have to abide by governmental standards. Unlike FOSHU regulations, however, companies may produce and distribute their products without the need of permission or notification of a governmental entity. From this, a new system was introduced to further deregulate the health food market in 2015 of Foods with Function Claims (FFC) [9]. The FFC system works by allowing "manufacturers to submit labeling to the Secretary-General of the Consumer Affairs Agency (CAA) in Japan that indicates the food is expected to have a specific effect on health, except for reducing the risk of diseases." This system is a notification system only. For an FFC product to "claim effectiveness on its label", it must have one of two methods of providing evidence: the first being randomized controlled clinical trials or systematic reviews (SRs) [9]. SRs are the preferred method for small and medium sized businesses as they are much less costly than clinical trials. SRs are a useful tool when assessing large quantities of research from biomedical research and can help address a specific question through its literature reviews, however, it still has its drawbacks; the use of an SR is limited to its overall quality and the quality of the methods used to assess it, in addition to the scientific methods used to conduct the review itself [9].

The quality of these SRs was analyzed in a study focusing on SRs before and after the CAA included a verification report in 2016 that was to be turned in with the SRs [11]. The study collected 49 FFC SRs posted on the CAA website from April 1st to October 27th of 2015 and compared them to SRs posted in 2016 after the verification report system was implemented. The SRs previous to the verification report system were noted to have "very poor 
descriptions and/or implementation of the registration, poor evaluations of publication bias, and questionable conclusions" [11]. While the study did show that there was some improvement in the SRs after the verification report system took effect, the improvement was not sizable. Four categories including a comprehensive literature search being performed and the characteristics of the study being included showed improvement from before. However, another 7 categories including assessment of scientific quality, duplication of study and extraction of data, and the assessment of possible bias were rated as "poor" or "very poor" [11]. Overall, the study showed an inadequate system of assessment for claims made under the FFC. There is a need for stronger regulations on SRs submitted with FFC claims. This study is an indicator of a larger problem within the nutritional health industry in Japan; unless companies are strictly monitored for the quality of their research and overall production, they are reluctant to change. Although the deregulation has brought new opportunities to smaller businesses in the market, it has also left many holes open for companies to exploit.

Issues with efficacy and public education: One prominent flaw within the domain of FOSHU is the lack of aftermarket research. That is, research performed after the release of a product in order to investigate its effects in an uncontrolled environment that is commonly found in the general public. Professor Masanori Suzuki from Waseda University in the Sport Sciences division found such issues within the system [12]. The main issue is the generalized marketing many companies use with FOSHU products. While some FOSHU products target specific populations suffering from specific issues such as the management of blood pressure and the reduction of the risk of neural tube defect, a large portion of those products make generalized health claims that apply to the general public. The two most prominent claims are related to modification of gastrointestinal conditions and triacylglycerols, which are related to obesity [12]. These are two conditions that are likely to affect a large portion of the population to some degree, giving these products a large market.

The problems with this are best seen in tea drinks advertised to fight metabolic syndrome, also known as obesity in the United States. These teas often contain resistant dextrin or polyphenol which work to inhibit digestion and absorption of dextrin along with the sugar ingested throughout a meal. The proposed mechanism being that those additions to the drink will prevent a large increase of blood glucose level that is seen during or after a meal, which works to prevent obesity and diabetes. However, while there was scientific evidence confirming the effectiveness of the tea, clinical trials were performed under very controlled conditions such as using rice balls for the meals and plain hot water as the control drink. The issue with the control drink is its inability to compare its effectiveness to regular tea, and the rice balls give quick spikes in blood glucose levels. These conditions rarely mimic the regular meals that are consumed by the general public [12].

During an independent experiment, Suzuki found that the health claim did not stand much ground. Using three different test meals of a pork rice bowl, a salmon lunch, and a hamburger steak lunch, along with two different teas, one containing resistant dextrin and the other with polyphenol and a control drink of green tea extracted with hot water, they tested effects the teas had on blood glucose levels in participants. The results showed no significant decrease in blood glucose levels differing from the control green tea. This shows that while the 
health claims put out by FOSHU are not completely without grounds, they are not produced with the lifestyles of consumers in mind [12]. This puts the value of FOSHU products into question. Is the increased price value supported by the results experienced by the general public? Although Suzuki's study was not published in a journal, the results were compelling, and he was not the only one who questioned the efficacy of FOSHU.

One big factor in analyzing FOSHU effectiveness is consumer compliance with instructions for consumption. However, the average consumer does not always know to follow the label instructions, or why they are so important. While there is a shortage of information on steps taken to educate the public on the proper use of FOSHU and the dangers of improper intake of the functional food products, there are a few studies detailing the level of ignorance of the public, as well as the dangers that the average consumer faces. Dr. Chiba from the National Institute of Health and Nutrition in Japan specializes in the department of Food Function and Labeling and has published a few papers on the topic of FOSHU. He notes that FOSHU can be a valuable tool when "consumers correct their lifestyle appropriately" [13]. However, it seems that many consumers of FOSHU products do not follow this guideline. A large percentage of consumers took FOSHU as a way to maintain their health and a smaller percentage used them for the prevention or treatment of disease. While FOSHU packages are labeled appropriately, only about $60 \%$ of consumers followed the directions, another $20 \%$ did not follow directions at all, and the remainder were unaware of the directions on the packaging, indicating that in that situation, "only $23.4 \%$ of users gained beneficial effects from FOSHU" [13]. Further analysis of the data showed the extent of FOSHU's effectiveness. Only $30.2 \%$ of users who modified their diet, along with $17.0 \%$ of those who modified their exercise routines and $10.1 \%$ of those who made no modifications on their lifestyle experienced beneficial effects from FOSHU. Moreover, the study revealed improper usage of FOSHU among consumers on medications, which has the potential to be harmful [13]. As a follow up study, the usage of FOSHU along medication to treat diseases and illnesses was examined. It was found that the percentage of those who use FOSHU to treat illnesses rose with age and the practice was significantly higher in patients actively seeking medical attention compared to those who are not [14]. Meanwhile, only $14.6 \%$ of these patients disclosed this to their physicians. FOSHU is often found in the form of common food, so the chance of interaction with medicine is small, and yet due to this potential, usage of FOSHU products should be disclosed to physicians [14]. Chiba's findings show that while there has been a great effort to gain public trust in FOSHU, proper use and warnings have not been stressed nearly enough. This adds another aspect to the study concerning the opinions of pharmacists regarding their patients' use of health products; not only do the pharmacists and possibly other health professionals have a poor understanding of these products, but patients also fail to follow specific instructions set by the manufacturers for optimal results. This leads to miscommunication that lowers the potential of FOSHU significantly.

The lack of knowledge of the public regarding the use of FOSHU has led to marginal results in consumers and a decrease in confidence in the products. A study concerning the usage of dietary oil products which are approved as a FOSHU product found that there was a lack of belief in the efficacy of FOSHU among female university students studying health sciences [14]. Out of 1223 participants, 47\% 
had experience using the products and 69\% used the FOSHU products because their families were also using them. The target individuals for these products were those with a body mass index of 23 or greater and while $49 \%$ of participants knew the requirements for product usage, only $13 \%$ were actually target individuals and less than $1 \%$ of those participants believed that the FOSHU products they were using are effective [15]. One major reason for the lack of belief in FOSHU could be attributed to non-target individuals using products specifically made for certain conditions, and especially with products such as oil, consistent quantities are difficult to consume. Therefore, the effects of the FOSHU product might be hard to notice [15]. Table 5 summarizes the criticisms of the FOSHU system for consumers.

Table 5: Shortcomings of the FOSHU approval process for consumers.

\section{Criticisms of FOSHU Process for Consumers}

- High Prices

- Due to lengthy approval process, products end up costing too much for lower-income families. This excludes large portions of population from benefiting from health effects.

- Lack of After Market Research

- Follow up research allows for refinements after products are released to increase efficacy and test in uncontrolled environments.

- No research results in products that do not mimic the uncontrolled setting of real-life consumption in the public.

- Consumers cannot most effectively benefit from FOSHU products.

- Lack of Education to the Public and Healthcare Professionals

- Most consumers do not properly follow label instructions or know why they are important.

- Many consumers do not use product for its intended use or in conjunction with appropriate lifestyle (i.e., diet and exercise).

- Only $14.6 \%$ of consumers know to disclose the use of these products to their physicians.

- Some health care professionals (pharmacists) lack knowledge and comfort with these products (i.e., adverse reactions with medications).

The Functional Food Center has placed a lot of effort into educating the public about functional foods, their uses, and their benefits. Along with publishing peer-reviewed journals, organizing international conferences, and creating educational materials such as textbooks used in universities, the Functional Food Center also created the Academic Society for Functional Foods and Bioactive Compounds (ASFFBC). The ASFFBC was established in order to unify the scientific and medical communityaround functional foods [2]. This is a critical step in the improvement of functional foods worldwide.

\section{CONCLUSIONS}

In the past, the Functional Food Center has investigated how the FOSHU system operates in Japan, and how the Functional Food Center's vision of functional foods should be regulated in the US. However, this article dug deeper in discovering the efficacy of the FOSHU system in practice. Specifically, in this review, the general market for FOSHU, the impacts of the FOSHU seal on consumer trust, as well 
as the shortcomings of the system have been discussed. The FOSHU regulation system on health claims has helped manage false or exaggerated health claims that were prevalent in the time before its implementation. Under FOSHU and its derivatives, the market for functional foods has been able to grow in Japan and trickle down to the rest of the world. Still, although FOSHU has been around for thirty years, its market is still rather limited in Japan. A large portion of its consumers are in the older age range, and as discussed before, socioeconomic factors do play a role in the consumption of those food products. This shows that there is still a significant portion of the population that does not have access to FOSHU products, either due to lack of knowledge or lacking abilities to purchase the products. Furthermore, from the limited aftermarket research found on FOSHU food products, there is a lack of proper consumption by consumers, as well as missing research for the efficacy and safety of these products in an uncontrolled setting. The consequences are reduced benefits from possibly well functional products. A pattern that has emerged in this review is the marketing of FOSHU towards a population that is too general. Although FOSHU packaging does provide information as to who target individuals are, the general public is not aware of the importance of the information. Providing more specific marketing along with better education regarding the limitations of the products can increase the overall function of FOSHU products.

Taking some of the possible routes of improvement suggested by the Functional Food Center, such as increase in public education in functional food and more specific instructions and duration of consumption might be realistic ways to improve overall results. This, along with the introduction of epidemiological studies post-market in order to assess the effectiveness of a functional food, can aid in the development of functional foods as a science around the world. In the United States specifically, the introduction of a functional food sector can provide a means to gain public trust in the health food they purchase. In order to avoid mistakes seen in the Japanese systems, encouraging not only after-market research, but research that challenges the system's efficacy can expose issues in an orderly manner and bring constructive change to food regulations.

This paper sought to review the effectiveness of the FOSHU system. However, there were limitations to the scope of information available. After-market research seems to be scarce in regard to FOSHU, and some sources found were in Japanese, making it difficult to use the information they contained. Instead, their abstracts were used to draw data and conclusions.

Abbreviations: FOSHU: Foods for Specified Health Uses, EU: European Union, MHLW: Ministry of Health Labor and Welfare, GMOs: Genetically modified organisms, FDA: Food and Drug Administration, FNFC: Foods with Nutrient Function Claims, FHC: Food with Health Claims, FFC: Food with Functions Claims, MWTP: marginal willingness to pay, CAA: Consumer Affairs Agency, SRs: systematic reviews, ASFFBC: Academic Society for Functional Foods and Bioactive Compounds.

Authors' Contributions: All authors contributed to this manuscript.

Conflict of Interest: The authors declare no conflict of interest.

Acknowledgements: No external funding was needed or given for this review article. 


\section{REFERENCES}

1. Díaz, L. D. Ruiz, V. F. and Cámara, M. An International Regulatory Review of Food Health-Related Claims in Functional Food Products Labeling. Journal of Functional Foods 2020, 68 doi:10.1016/j.jff.2020.103896.

2. Sadohara R., and Martirosyan D. Functional Food Center's vision on functional foods definition and science in comparison to FDA's health claim authorization and Japan's Foods for Specified Health Uses. Functional Foods in Health and Disease 2020, 10(11): 465-481. doi: 10.31989/ffhd.v10i11.753

3. Ono, M. and Ono, A. Impacts of the FoSHU (Food for Specified Health Uses) system on food evaluations in Japan. The Journal of Consumer Marketing 2015, 32(7): 542-550. doi: 10.1108/JCM-09-2014-1144

4. Hirogaki, M. Estimating consumers' willingness to pay for health food claims: A conjoint analysis. International Journal of Innovation, Management and Technology 2013, 4(6):541-546 doi:10.7763/ijimt.2013.v4.458.

5. Futara, R. Takahiro, H. Who chooses functional food?: Socio-demographic effects and food category difference estimated from scanner-panel data. Food Laws 2020, doi:10.2139/ssrn.3567617

6. The Foshu logo, a category that Japan applies to certified healthy foods. (https://yguamoringa.com/losalimentos-funcionales/foshu/) Retrieved March 18, 2021.

7. Asahina, Y. Hori, S. and Sawada,Y. Community pharmacists' attitudes relating to patients' use of health products in Japan. Int J Clin Pharm 2012, 34:529-537. doi:10.1007/s11096-012-9640-4

8. Kubomura, K. R. Functional foods: A view from japan. Cereal Foods World 2007, 52:86-87.

9. Ministry of Health, Labour and Welfare: Food with Health Claims, Food for Special Dietary Uses, and Nutrition

Labeling [www.mhlw.go.jp/english/topics/foodsafety/fhc/02.ht ml] Retrieved March 15, 2021
10. Hasler, C. M. Regulation of functional foods and nutraceuticals: A global perspective. IFT Press 2005.

11. Kamioka, H. Tsutani, K. Origasa, H. Yoshizaki, T. Kitayuguchi, J. Shimada, M. Wada, Y. and TakanoOhmuro, H. Quality of systematic reviews of the foods with function claims in japan: Comparative before- and after-evaluation of verification reports by the consumer affairs agency. Nutrients 2019, 11:1583.

12. Suzuki, M. Abolish the FOSHU! evidence too ambiguous to say 'food for you.' Waseda online, [yab.yomiuri.co.jp/adv/wol/dy/opinion/society_10011 2.html] Retrieved March 15, 2021

13. Chiba, T. Sato, Y. Nakanishi, T. Yokotani, K. Karino, T. Suzuki, S. Umegaki, K. Inappropriate application of food for specified health uses. Journal of Japanese Society of Nutrition and Food Science 2014, 67(4):177-184 doi:10.4327/jsnfs.67.177.

14. Chiba, T. Sato, Y. Suzuki, S. Umegaki, K. Concomitant use of medicines with food for specified health uses. Journal of Japanese Society of Nutrition and Food Science 2015, 68(4):147-155 doi:10.4327/jsnfs.68.147.

15. Matsumoto, K. Murakami, T. Ishihara, K. Okamura, K. Yaguchi, Y. Ono, C. Fujii,H. and Hashiba, N. The current situation regarding the use of dietary oil products as a food for specified health use (FOSHU) among female university students studying health sciences. Journal of Japanese Society of Nutrition and Food Science 2015, 68(5):233-241. doi:10.4327/jsnfs.68.233. 